\title{
A novel gene, algK, from the alginate biosynthetic cluster of Pseudomonas aeruginosa
}

\author{
Simon J. Aarons, ${ }^{1}+$ lan W. Sutherland, ${ }^{1}$ A. M. Chakrabarty ${ }^{2}$ and \\ Maurice P. Gallagher ${ }^{1}$
}

Author for correspondence: Maurice P. Gallagher. Tel: +44131650 5409. Fax: +44131668 3870. e-mail: mp.gallagher@ed.ac.uk

1 Institute of Cell and Molecular Biology, Division of Biology, University of Edinburgh, West Mains Road, Edinburgh EH9 3JR, UK

2 Department of Microbiology and Immunology, University of Illinois College of Medicine, Chicago, IL 60612, USA

\begin{abstract}
Colonization of the cystic fibrosis lung by Pseudomonas aeruginosa is greatly facilitated by the production of an exopolysaccharide called alginate. Many of the enzymes involved in alginate biosynthesis are clustered in an operon at $34 \mathrm{~min}$ on the $\boldsymbol{P}$. aeruginosa chromosome. This paper reports the nucleotide sequence of a previously uncharacterized gene, algK, which lies between the alg44 and algE genes of the operon. DNA sequencing data for algK predicted a protein product of approximately $52.5 \mathrm{kDa}$ which contains a putative 27 amino acid $\mathbf{N}$-terminal signal sequence and a consensus cleavage and lipid attachment site for signal peptidase II. Expression of algK using either $\mathrm{T7}$ or tac promoter expression systems, and in vivo labelling studies with ${ }^{35}$ S]methionine, indicated that algK encodes a polypeptide of approximately $53 \mathrm{kDa}$ which is processed to a mature protein of approximately $50 \mathrm{kDa}$ when expressed in Escherichia coli or $P$. aeruginosa, in agreement with the nucleotide sequence analysis. Results from an AlgK- $\beta$-lactamase fusion survey support this interpretation and also provide evidence that mature AlgK is entirely periplasmic and is probably membrane-anchored.
\end{abstract}

Keywords: AlgK, alginate, exopolysaccharide, Pseudomonas aeruginosa, cystic fibrosis

\section{INTRODUCTION}

Pseudomonas aeruginosa is an opportunistic pathogen which can cause severe infections of the respiratory tract, of burn wounds and of the urinary tract. In patients with cystic fibrosis (CF), $P$. aeruginosa causes a pulmonary infection which generally remains intractable both to antibiotic therapy and to elimination by the immune system.

The persistence of $P$. aeruginos $a$ in the CF lung depends heavily on its ability to form microcolonies, embedded within a polyanionic biofilm of alginate exopolysaccharide (Lam et al., 1980). The pattern of microcolony formation has profound implications for the course of the disease, as the alginate biofilm protects $P$. aeruginosa from phagocytosis, impedes antibiotic pen-

†Present address : Department of Microbiology, University College, Cork, Ireland.

Abbreviation: CF, cystic fibrosis.

The EMBL accession number for the algK sequence is $\mathrm{X} 99206$. etration and also facilitates bacterial adherence to the respiratory tract. The progressive emergence of mucoid strains therefore allows the establishment of chronic $P$. aeruginosa infection within the CF lung, ultimately leading to irreversible lung damage, respiratory failure and death. As a result, this pathogen has proved to be a major cause of morbidity and mortality amongst CF patients.

Alginate from $P$. aeruginosa is composed of a linear copolymer of 1,4- $\beta$-linked D-mannuronic acid and its C-5 epimer, L-guluronic acid, in which the mannuronic acid residues are variably modified with $\mathrm{O}$-acetyl groups (Skjåk-Bræk et al., 1986). Much of the pathway for alginate biosynthesis has been defined. The majority of the enzymes involved in alginate biosynthesis are clustered in an $18 \mathrm{~kb}$ operon (Chitnis \& Ohman, 1993) at $34 \mathrm{~min}$ on the $P$. aeruginosa chromosomal map. The operon encodes proteins such as the dual-function enzyme phosphomannose isomerase-GDP mannose pyrophosphorylase (algA; Shinabarger et al., 1991) and also GDP-mannose dehydrogenase (algD; Deretic et al., 1987). Other genes identified in the alginate biosynthetic 
cluster encode a C5-mannuronate epimerase which is responsible for the incorporation of L-guluronate residues into alginate (algG; Franklin et al., 1994), an Oacetylase which esterifies mannuronate residues (algF; Shinabarger et al., 1993), a D-mannuronate-specific alginate lyase (algL; Boyd et al., 1993; Schiller et al., 1993) and an outer-membrane pore which is considered to mediate alginate excretion (algE; Chu et al., 1991; Rehm et al., 1994). Despite this knowledge, however, the mechanism by which alginate polymerization and export occur remains poorly understood.

Two regions remain uncharacterized within the $34 \mathrm{~min}$ biosynthetic cluster. The first is a region of approximately $2 \mathrm{~kb}$ between alg44, a gene which encodes a putative hydrophobic protein of undefined function (Maharaj et al., 1993), and algE. The second region (approximately $2.5 \mathrm{~kb}$ ) lies between $\operatorname{alg} L$ and $\operatorname{alg} F$, and is thought to encode an acyl-carrier protein (May \& Chakrabarty, 1994). In this paper we describe the cloning and sequencing of the first of these two regions and report the identification of a new gene which we have called algK. We show, in both Escherichia coli and $P$. aeruginosa, that algK encodes a poorly expressed preprotein of approximately $53 \mathrm{kDa}$ which is processed to form a smaller mature polypeptide. We also provide evidence, obtained using fusion proteins, that mature AlgK adopts an entirely periplasmic location and probably undergoes an $\mathrm{N}$-terminal post-translational modification.

\section{METHODS}

Bacterial strains and media. Bacterial strains and plasmids used in this study are described in Table 1. E. coli and $P$. aeruginosa were routinely cultured in LB broth or on minimal agar containing $\mathrm{M} 9$ medium (per litre: $1 \mathrm{~g} \mathrm{NH}_{4} \mathrm{Cl}, 3 \mathrm{~g}$ $\mathrm{KH}_{2} \mathrm{PO}_{4}, 1.6 \mathrm{~g} \mathrm{Na}_{2} \mathrm{HPO}_{4}, 1 \mathrm{ml} 1 \mathrm{M} \mathrm{MgSO}_{4}, 50 \mu \mathrm{l} 1 \mathrm{M} \mathrm{CaCl}$ ) supplemented with $0.08 \%(\mathrm{w} / \mathrm{v})$ glycerol, $0.4 \%(\mathrm{w} / \mathrm{v})$ glucose, $0.04 \%(\mathrm{w} / \mathrm{v})$ thiamin and antibiotics, where appropriate. The latter medium was used to select for $P$. aeruginosa following triparental matings with $E$. coli. Antibiotics were used at the following concentrations (per $\mathrm{ml}$ ) unless otherwise stated: ampicillin, $50 \mu \mathrm{g}$ (200 $\mu \mathrm{g}$ for $P$. aeruginosa); tetracycline, $15 \mu \mathrm{g}$; kanamycin, $50 \mu \mathrm{g}$; chloramphenicol $5 \mu \mathrm{g}$. Alginate production was assessed visually from colonies grown on LB agar or MAP medium (Franklin et al., 1994).

Triparental matings were used to mobilize plasmids from $E$. coli to $P$. aeruginosa using the conjugation helper plasmid pRK2013, as described previously (Darzins \& Chakrabarty, 1984).

DNA manipulations and nucleotide sequencing. General DNA manipulations were performed as described by Sambrook et al. (1989). The plasmid pRM812 (Table 1) contains a $9 \mathrm{~kb}$ HindIII fragment encompassing a region of the alginate gene cluster from algD to algG in phagemid pUC119. A SmaI-EcoRI digest of pRM812 yielded a $2.0 \mathrm{~kb}$ DNA fragment which was initially subcloned into pBluescript to form pAA1. DNA sequences were determined by the dideoxy chain-termination procedure (Sanger et al., 1977). Both DNA stands were completely sequenced using fragments from pAA1 (see Fig. 1), subcloned into M13mp19, or following exonuclease III and nuclease S1 digestion of the pJBS633 derivatives, pAA26 or pAA22, which contain the entire SmaI-EcoRI fragment from pRM812 (Fig. 1) in opposite orientations. pAA26 carries a BamHI-EcoRV fragment which was subcloned from pAA1. Construction of pAA22 is described later.

Construction of plasmids for expressing algK. Expression vectors pAA13 and pAA15 were constructed by subcloning of algK on a Bam HI-HindIII fragment from pAA1 into the vectors pT7-3 and pT7-5, respectively. pAA20, which carries the complete algK ORF, was constructed by PCR amplification, using pAA1 as a template and primers 1 (5'GGTACCCGCATATGAAGATGCCCATC- $\left.3^{\prime}\right)$ and 2 (5'GGGGATCCTCATAGGTTTCTGGCTCTTCTT- $3^{\prime}$ ). The primers were synthesized such that the amplified fragment contained an NdeI site overlapping the translational start codon of the algK ORF, and also a BamHI site at the $3^{\prime}$ end (Cterminus) to facilitate cloning of the PCR product into the NdeI-BamHI sites of pT7-7.

pAA23 was constructed by subcloning PCR-amplified algK together with the strong pT7-7 ribosome-binding site (RBS; from vector pAA20), using primers 2 and 3 (5'CAACGATATCCCTCTAGAAAA-3'), into pMMB66(EH). The $5^{\prime}$ end of primer 3 contains an EcoRV site to facilitate cloning of the PCR product into the SmaI and BamHI sites of pMMB66(EH). The amplified product contains the ATG from the strong RBS of pT7-7 together with the immediate 44 upstream bases from this vector (Tabor, 1990).

Expression of AlgK in E. coli and P. aeruginosa. AlgK was expressed under the control of the T7 promoter in E. coli BL21(DE3)[pLysS] cells, as described by Studier \& Moffatt (1986). Following overnight growth in LB broth at $37^{\circ} \mathrm{C}, 50 \mu \mathrm{l}$ of culture was inoculated into $5 \mathrm{ml}$ aliquots of LB broth containing the appropriate antibiotics and incubated for a further $2 \mathrm{~h}$ at $37^{\circ} \mathrm{C}$. Aliquots $(1 \mathrm{ml})$ of uninduced culture were harvested by microfugation and stored frozen until further analysis. The remaining culture was induced by the addition of $1 \mathrm{mM}$ IPTG and $1 \mathrm{ml}$ aliquots of induced culture were subsequently sampled at hourly intervals and stored until analysis. Conditions for expression of pMMB66 (EH) derivatives were essentially as described for $\mathrm{pT} 7$ vectors, with the exception that HB101 and PA8873 were used as the plasmid hosts.

In vivo labelling of AlgK with ${ }^{35} \mathrm{~S}$ ]methionine. The $\mathrm{T} 7$ expression system described by Tabor (1990) was used to preferentially radiolabel algK products expressed from pAA20. Cultures of BL21(DE3)[pLysS] containing pAA20 were grown to mid-exponential phase at $37^{\circ} \mathrm{C}$ in LB broth, and $1 \mathrm{ml}$ samples were collected by centrifugation, washed twice in $\mathrm{M} 9$ medium and resuspended in $1 \mathrm{ml} \mathrm{M} 9$ medium supplemented with glucose $(0.4 \%, \mathrm{w} / \mathrm{v})$, thiamin $(0.04 \%$, $\mathrm{w} / \mathrm{v}$ ), 18 common amino acids (lacking methionine and cysteine; each at $40 \mu \mathrm{g} \mathrm{m}^{-1}$ ), and appropriate antibiotics. Cells were incubated for a further $1 \mathrm{~h}$ and then IPTG was added $(1 \mathrm{mM})$ to permit transcription from the T7 RNA polymerase gene. The incubation was continued for a further $45 \mathrm{~min}$ or alternatively, after $15 \mathrm{~min}$ rifampicin $\left(200 \mu \mathrm{g} \mathrm{ml}^{-1}\right)$ was added and the incubation was continued for a further $30 \mathrm{~min}$ at $37^{\circ} \mathrm{C}$. The $\left.{ }^{35} \mathrm{~S}\right]$ methionine $[10 \mu \mathrm{Ci}, 800 \mathrm{Ci}$ $(370 \mathrm{kBq}) \mathrm{mmol}^{-1}$; Amersham] was added, and cells were incubated at $37^{\circ} \mathrm{C}$ for a further 5,10 or $20 \mathrm{~min}$ before harvesting.

In pulse-chase experiments, in which algK was expressed under the tac promoter in $P$. aeruginosa PA8873(pAA23), bacteria were grown for $18 \mathrm{~h}$ in LB broth at $37^{\circ} \mathrm{C}$. Cells from $0.75 \mathrm{ml}$ culture were collected by centrifugation $(5000 \mathrm{~g}$, 
Table 1. Bacterial strains, plasmids and phages

\begin{tabular}{|c|c|c|}
\hline $\begin{array}{l}\text { Strain/plasmid/ } \\
\text { phage }\end{array}$ & Relevant characteristics $\dagger$ & Source/reference \\
\hline \multicolumn{3}{|l|}{ Bacteria } \\
\hline \multicolumn{3}{|l|}{ E. coli } \\
\hline BL21(DE3) & $\mathrm{F}^{-} o m p^{+} \mathrm{r}_{\mathrm{B}}^{-} \mathrm{m}_{\mathrm{B}}^{-}(\mathrm{DE} 3$ is a $\lambda$ lysogen bearing lacl lacUV5 gene1) & Studier et al. (1990) \\
\hline HB101 & $\begin{array}{l}\mathrm{F}^{-} \text {bsdS20 }\left(\mathrm{r}_{\mathrm{B}}^{-} \mathrm{m}_{\mathrm{B}}^{-}\right) \operatorname{supE44} \text { recA13 ara-14 proA2 rpsL20 }\left(\mathrm{Str}^{\mathrm{R}}\right) \text { xyl-5 mtl-5 } \\
\text { supE44 } \lambda^{-}\end{array}$ & Maniatis et al. (1982) \\
\hline JM101 & thi $\Delta$ (lac-proAB) $\left[\mathrm{F}^{\prime}-\right.$ traD36 proAB lacl $\left.{ }^{\mathrm{q}} \mathrm{Z} \Delta \mathrm{M} 15\right]$ & Yanisch-Perron et al. (1985) \\
\hline \multicolumn{3}{|l|}{ P. aeruginosa } \\
\hline PA8873 & alg- $A$, his-1 & Darzins \& Chakrabarty (1984) \\
\hline PAB & Constitutively secretes alginate & A. Linker \\
\hline PABK & Carries a chromosomal algK': :pBR325 insertion & This study \\
\hline \multicolumn{3}{|l|}{ Plasmids } \\
\hline pAA1 & $\begin{array}{l}\text { pBluescript derivative, containing region from alg44 to algE on } \\
\text { Smal-EcoRI fragment }\end{array}$ & This study \\
\hline pAA13 & $\begin{array}{l}\text { pT7-3 derivative, containing subcloned region from alg44 to algE on } \\
\text { Bam HI-HindIII fragment from pAA1 }\end{array}$ & This study \\
\hline pAA15 & $\begin{array}{l}\text { pT7-5 derivative containing subcloned region from alg44 to algE on } \\
\text { Bam } \mathrm{HI}-\text { HindIII fragment from pAA1 }\end{array}$ & This study \\
\hline pAA20 & $\begin{array}{l}\text { pT7-7 derivative containing } N d e I-B a m \text { HI fragment amplified from pAA } 1 \\
\text { by primers } 1 \text { and } 2 \text { encoding AlgK }\end{array}$ & This study \\
\hline pAA22 & $\begin{array}{l}\text { pJBS633 derivative containing EcoRV-Bam HI fragment amplified from } \\
\text { pAA } 20 \text { by primers } 3 \text { and } 4 \text { encoding AlgK }\end{array}$ & This study \\
\hline pAA23 & $\begin{array}{l}\text { pMMB66(EH) derivative containing EcoRV-BamHI fragment amplified } \\
\text { from pAA } 20 \text { by primers } 3 \text { and } 2 \text { encoding AlgK }\end{array}$ & This study \\
\hline pAA26 & $\begin{array}{l}\text { pJBS633 derivative subcloned region from algE to alg44 on BamHI-EcoRV } \\
\text { fragment from pAA1 }\end{array}$ & This study \\
\hline pAA31 & pBR325 carrying a $410 \mathrm{bp}$ PstI fragment of algK & This study \\
\hline pAA32 & pMMB66(EH) carrying a Smal-HindIII algKE fragment & This study \\
\hline pAA33 & pAA32 carrying a HindIII algA fragment & This study \\
\hline pAA35 & pAA22 derivative expressing $\mathrm{AlgK}-\beta$-lactamase fusion protein & This study \\
\hline pMPG32 & pJBS633 with the PvuII site replaced by a SmaI site & This study \\
\hline pBluescript & E. coli cloning plasmid, ColE1 Amp ${ }^{R}$ lacZ $\alpha$ & Short et al. (1988) \\
\hline pJBS633 & $\mathrm{Tet}^{\mathrm{R}} \mathrm{Kan}^{\mathrm{R}}$ 'blaM & Broome-Smith \& Spratt (1986) \\
\hline pLysS & $\mathrm{Cml}^{\mathrm{R}}$, pACYC184 derivative containing T7 lysozyme gene & Studier et al. (1990) \\
\hline pMMB66(EH) & Broad-host-range expression vector, $\mathrm{Amp}^{\mathrm{R}}$ lacl $^{\mathrm{q}} \mathrm{tac}$ & Fürste et al. (1986) \\
\hline pRK2013 & ColE1 $\mathrm{Tra}^{+}-(\mathrm{RK} 2) \mathrm{Kan}^{\mathrm{R}}$ & Figurski \& Helinski (1979) \\
\hline pRM812 & pUC119 derivative containing $9 \mathrm{~kb}$ HindIII algD-algG fragment & Provided by R. Maharaj \\
\hline pT7-3 & E. coli expression vector, $A m p^{R}$ ColE1 $p_{\mathrm{T} 7}$ & Tabor $(1990)$ \\
\hline pT7-5 & E. coli expression vector, $A m p^{R}$ ColE1 $p_{T 7}$ & Tabor $(1990)$ \\
\hline pT7-7 & E. coli expression vector, $\mathrm{Amp}^{\mathrm{R}} \mathrm{ColE} 1 p_{\mathrm{T} 7}$ and RBS & Tabor $(1990)$ \\
\hline \multicolumn{3}{|l|}{ Phages } \\
\hline M13mp19 & E. coli cloning vector, $l a c Z \alpha$ lacI & Yanisch-Perron et al. (1985) \\
\hline $\mathrm{R} 408$ & Helper phage, gene 2 & Russel et al. (1986) \\
\hline
\end{tabular}

† $\mathrm{Alg}^{-}$, non-mucoid; $\mathrm{Tra}^{+}$, transfer by conjugation; $\mathrm{Amp}^{\mathbf{R}}$, ampicillin resistance; $\mathrm{Tet}^{\mathrm{R}}$, tetracycline resistance; Kan ${ }^{R}$, kanamycin resistance; $\mathrm{Cml}^{\mathrm{R}}$, chloramphenicol resistance; $\mathrm{RBS}$, ribosome-binding site.

$10 \mathrm{~min}$ ), washed with $\mathrm{M} 9$ medium, resuspended in $3 \mathrm{ml} \mathrm{M} 9$ medium supplemented as before with glucose and thiamin and then incubated at $37^{\circ} \mathrm{C}$ for $2 \mathrm{~h}$. IPTG was added, followed by incubation for $30 \mathrm{~min}$. $\left[{ }^{35} \mathrm{~S}\right]$ Methionine $[10 \mu \mathrm{Ci} ; 800 \mathrm{Ci}$ (29.6 TBq) $\mathrm{mmol}^{-1}$; Amersham] was added, and cells were incubated at $37^{\circ} \mathrm{C}$ for $2 \mathrm{~min}$. Unlabelled L-methionine $(0.1 \%$, $\mathrm{w} / \mathrm{v}$ ) was then added, and samples were withdrawn at suitable time intervals. Samples were analysed by SDS-PAGE and autoradiography.
Construction of AlgK'-' $\boldsymbol{\beta}$-lactamase fusion proteins. pAA22 was used for construction of fusion proteins; it was prepared by amplification of algK from pAA20 with primer 3 and primer 4 (5'-CGGGATCCAGCTGTAGGCTTTCTGGCTCTTCTT-3'). The amplified algK product contains the pT7-7-derived RBS at the $5^{\prime}$ end and a PvuII restriction site at the $3^{\prime}$ end (replacing the TGA stop codon), which is followed by a BamHI site downstream. The amplified fragment was cloned into the EcoRV-BamHI sites of pMPG32 (see below) 


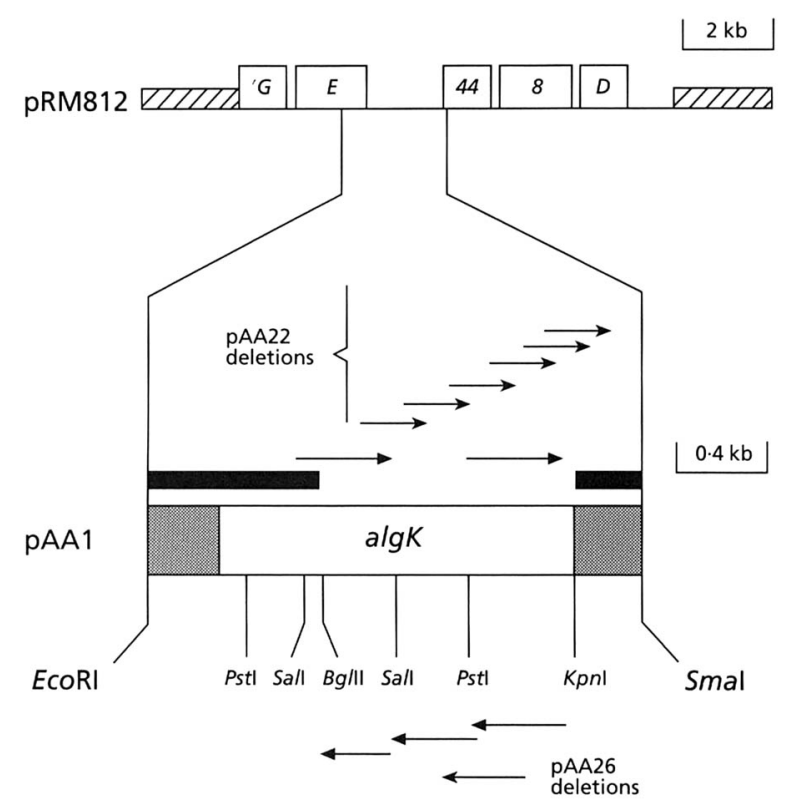

Fig. 1. The construction of vector pAA1 from $p R M 812$ and the respective internal restriction sites present in this region are shown at the top. The sequencing strategy applied to the unsequenced region between alg44 and algE is indicated. The flat-headed arrows show the extent and direction of the sequence obtained from specific M13mp19 subclones and the barbed arrows indicate sequence obtained following exonuclease III deletion of plasmids pAA22 and pAA26. The regions of DNA sequence reported previously (Chu et al., 1991; Maharaj et al., 1993) are indicated by black bars. pUC119 vector DNA of pRM812 is indicated by hatched shading.

to form pAA22. (pAA35 was constructed by deletion of a PvuII-SmaI fragment from pAA22.)

Unidirectional digestion of pAA22, using exonuclease III and S1 nuclease, was carried out as described by Henikoff (1987), with appropriate modifications described for pJBS633 (Broome-Smith \& Spratt, 1986). Essentially, pAA22 was completely digested with $S p h I$ and BamHI to allow unidirectional digestion into the algK gene from the BamHI position by exonuclease III followed by S1 nuclease. The reaction products were ligated and transformed into $E$. coli JM101, selecting for kanamycin resistance. Recombinants which were predicted to have an 'in-frame' AlgK- $\beta$-lactamase fusion were identified by their ability to grow when $6 \mu \mathrm{l}$ of overnight culture was spotted onto agar containing $200 \mu \mathrm{g}$ ampicillin $\mathrm{ml}^{-1}$ (Broome-Smith \& Spratt, 1986).

The minimum inhibitory concentration (MIC) for single cells of $E$. coli JM101 containing pAA22-derived plasmids was subsequently determined by spotting $4 \mu \mathrm{l}$ of a $10^{-5}$ dilution of an overnight culture (about 40 bacteria) onto LB agar plates containing a range of concentrations of ampicillin. The MIC represented the lowest concentration of ampicillin that prevented growth of the bacterial colonies after overnight incubation at $37^{\circ} \mathrm{C}$ (Broome-Smith \& Spratt, 1986).

Dideoxy sequencing of algK'-blaM fusion junctions was carried out on single-stranded plasmid DNA, obtained from pJBS633 derivatives by infecting cells with helper phage R408 (Russel et al., 1986), using the oligonucleotide $5^{\prime}$ CTGTGCACCCAACTGA-3', which primes from codons 14 to 18 of the mature form of TEM $\beta$-lactamase across the fusion junction (Broome-Smith \& Spratt, 1986). The pJBS633 used is a variant of that previously mentioned (Broome-Smith \& Spratt, 1986) in which the linker sequence $5^{\prime}$ CCCGGGCCCGGG-3', which contains a Smal site, has been inserted within the PvuII site of the vector, forming pMPG32.

Insertional inactivation of algK and complementation studies. An algK fragment of approximately $460 \mathrm{bp}$ was amplified from pAA22 using primer $7 \quad\left(5^{\prime}-\right.$ CGCTGCAGGACCCGCGCAAGGC- $3^{\prime}$ ), which contains a PstI site towards the $5^{\prime}$ end, and primer 4 , which primes the complementary strand from the algK TGA stop codon. A natural Pst I site occurs in algK (nucleotides 1614-1619, Fig. 2) and therefore digestion of the PCR product with Pst gave rise to a $410 \mathrm{bp}$ fragment which was subcloned into the corresponding site of the blaM gene of pBR325. HB101 cells carrying the resulting plasmid, pAA31, were triparentally mated with $P$. aeruginosa strain $\mathrm{B}$ (PAB) which constitutively secretes alginate. Single homologous recombinants were selected on minimal plates, containing $200 \mu \mathrm{g}$ tetracycline $\mathrm{ml}^{-1}$, and plasmid integration into the chromosome was confirmed by Southern hybridization (Southern, 1975), by probing with a fragment of the $\mathrm{cml}$ gene from pBR325. The resulting isolates $(\mathrm{PABK})$ were examined visually for alginate production on LB agar or on MAP medium, which promotes alginate production (Franklin et al., 1994).

Complementation studies were carried out in PABK with plasmid-encoded algKEA. A Smal-HindIII fragment which spans from the $3^{\prime}$ end of alg44 into algG, and contains the entire algKE region, was initially cloned from pRM812 into the broad-host-range vector pMMB66(EH), forming pAA32. The HindIII fragment from pAD4038 which carries the algA gene was then inserted into the corresponding site in pAA32. The resulting plasmid, pAA33, was mobilized into PABK by triparental mating, as before and exconjugants were selected on minimal agar containing tetracycline and ampicillin (each at $200 \mu \mathrm{g} \mathrm{ml}^{-1}$ ). Expression of algKEA was induced from the ptac promoter of pAA33 on LB plates or MAP plates, with $1 \mathrm{mM}$ IPTG, and colonies were examined for alginate production.

SDSPAGE and immunoblotting. Overnight cultures bearing the required plasmid were harvested and electrophoresed in the presence of SDS (Laemmli, 1970). Following electrophoresis, proteins were either stained with Coomassie brilliant blue, visualized by autoradiography, or transferred by electroblotting to a nitrocellulose membrane (Towbin et al., 1979). Immunoblotting procedures were carried out with anti- $\beta$ lactamase antisera ( 5 prime to 3 prime Inc.) and alkalinephosphatase-conjugated anti-rabbit IgG (whole molecule; Sigma). The detection of bound antisera by alkaline phosphatase staining was carried out as described by Knecht \& Dimond (1984).

\section{RESULTS}

\section{Identification of a new gene, algK, within the 34 min alginate gene cluster of $\boldsymbol{P}$. aeruginosa}

The uncharacterized region upstream of algE (which encodes the alginate-permeable outer-membrane pore) within the $34 \mathrm{~min}$ alginate gene cluster of $P$. aeruginosa was selected for sequence analysis. Studies were confined to a SmaI-EcoRI fragment (approximately $2 \mathrm{~kb}$ ) which contains the entire uncharacterized segment between alg44 and algE, together with some flanking DNA (see Fig. 1). This fragment was isolated from pRM812 and 


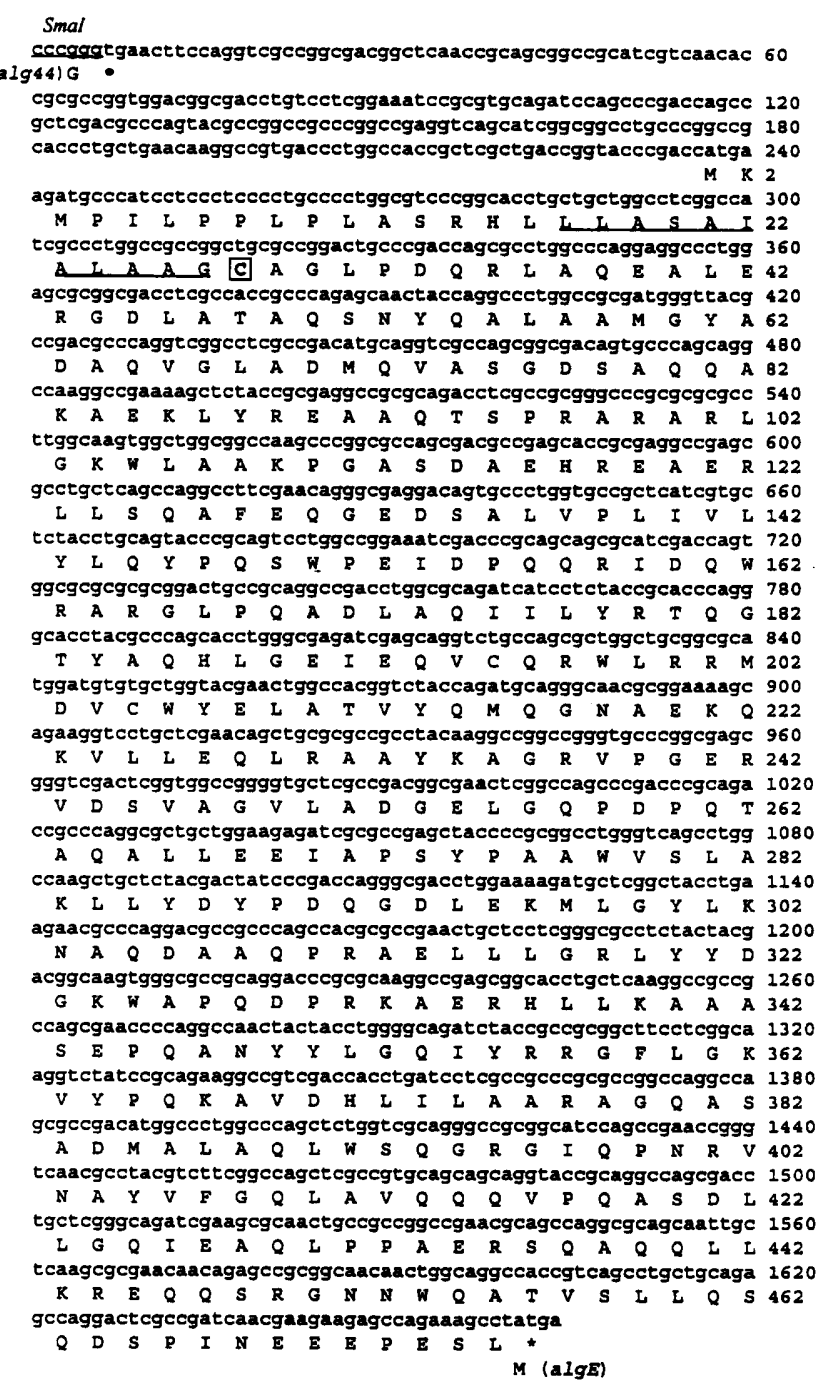

Fig. 2. Nucleic acid sequence and predicted amino acid sequence of the algK ORF. The sequence is shown from the Smal site (lower-case and underlined) of the C-terminal end of alg44 to the translation initiation codon of algE. Amino acids are shown by the standard one-letter abbreviations beneath the nucleotide sequence. Termination codons are designated by asterisks. The proposed cleavage signal recognized by leader peptidase II is underlined and the adjacent cysteine (C) residue required for lipid attachment is boxed.

was then subcloned into pBluescript to form vector pAA1. Sequence analysis revealed a single ORF (Fig. 2) of $1425 \mathrm{bp}$, in the same transcriptional orientation as the other genes of the operon, which encoded a putative protein of 475 amino acids with a predicted molecular mass of $52470 \mathrm{Da}$. We have named this gene algK. The ORF starts at an ATG codon 227 bp downstream from the stop codon of alg44 (Maharaj et al., 1993) and terminates at a TGA stop codon, which overlaps with the ATG translational start codon of algE (Chu et al., 1991), suggesting that these two genes are translationally coupled. Analysis of codon usage showed a high G + C content (approximately $70 \mathrm{~mol} \%$ ) with a particularly high $\mathrm{G}+\mathrm{C}$ bias in the third position $(93 \mathrm{~mol} \%$ ), which is a typical characteristic of $P$. aeruginosa DNA (Minton et al., 1984). The inferred amino acid sequence of AlgK predicted that the protein contained $46 \%, 31 \%, 11 \%$ and $11 \%$ non-polar, hydrophilic, acidic and basic residues, respectively. Overall the protein has a predicted isoelectric point of $5 \cdot 64$. The AlgK amino acid sequence was used to perform a homology search using the GenBank database, but no significant similarities were identified. We also observed that the amino acid sequence of $\mathrm{AlgK}$ contained a putative signal peptide at the $\mathrm{N}$-terminus (underlined in Fig. 2). This signal sequence contained the consensus pattern for cleavage and lipidation, associated with lipoproteins which are processed by leader peptidase II (Hayashi et al., 1984; Pugsley, 1993) with the cleavage site (Ala Gly ${ }^{ل} \mathrm{Cys}$ ) at the $3^{\prime}$ end of the signal sequence. This suggests that AlgK may be initially synthesized as a precursor (pre-AlgK) of about $53 \mathrm{kDa}$ and then processed by signal peptidase II to a $50 \mathrm{kDa}$ mature, membrane-anchored, lipoprotein.

\section{Expression of algK in $E$. coli and $P$. aeruginosa}

In order to substantiate our findings, we examined whether the region between $a \lg E$ and alg 44 produced a polypeptide of the predicted molecular size. The initial expression studies of $\operatorname{alg} K$ were performed using the vectors pT7-3 and pT7-5. A BamHI-HindIII DNA fragment from pAA1 (containing the entire SmaI-EcoRI fragment from $\mathrm{pRM}$ 812) was therefore subcloned into pT7-3 and pT7-5 to form plasmids pAA13 and pAA15, respectively. These plasmids were transformed into E. coli BL21(DE3)[pLysS] and T7 RNA polymerase was induced with IPTG (Sambrook et al., 1989). Protein samples from BL21(DE3)[pLysS, pAA13] or BL21(DE3)[pLysS, pAA15] were separated by SDSPAGE and stained with Coomassie brilliant blue. $\beta$ Lactamase was over-expressed from pAA13 but no novel protein bands were seen from samples containing pAA15 (data not shown). This suggested that the T7 RNA polymerase was functioning properly but that AlgK might be translated inefficiently.

In order to evaluate this possibility and to confirm that the ORF was correctly determined, algK was subcloned into vector pT7-7 in order to increase the efficiency of translation. pT7-7 differs from pT7-3 and pT7-5 in having a strong RBS containing an NdeI sequence, and a translational start site to enhance expression of adjacent coding information. The algK gene was therefore amplified using PCR technology, with pAA1 as the DNA template, and inserted into pT7-7. Synthetic oligonucleotide primers were designed, such that the upstream primer (primer 1) contained an NdeI site encompassing the predicted ATG translational start codon of algK and the downsteam primer (primer 2) contained a BamHI site adjacent to the complementary sequence of the algK TGA stop codon. The amplified fragment was cloned into the corresponding sites of pT7-7 (forming pAA20), placing algK under the inducible T7 promoter in such a manner that the complete algK ORF was expressed from the vector-encoded RBS. Cultures of BL21(DE3)[pLysS, pAA20] were induced as 


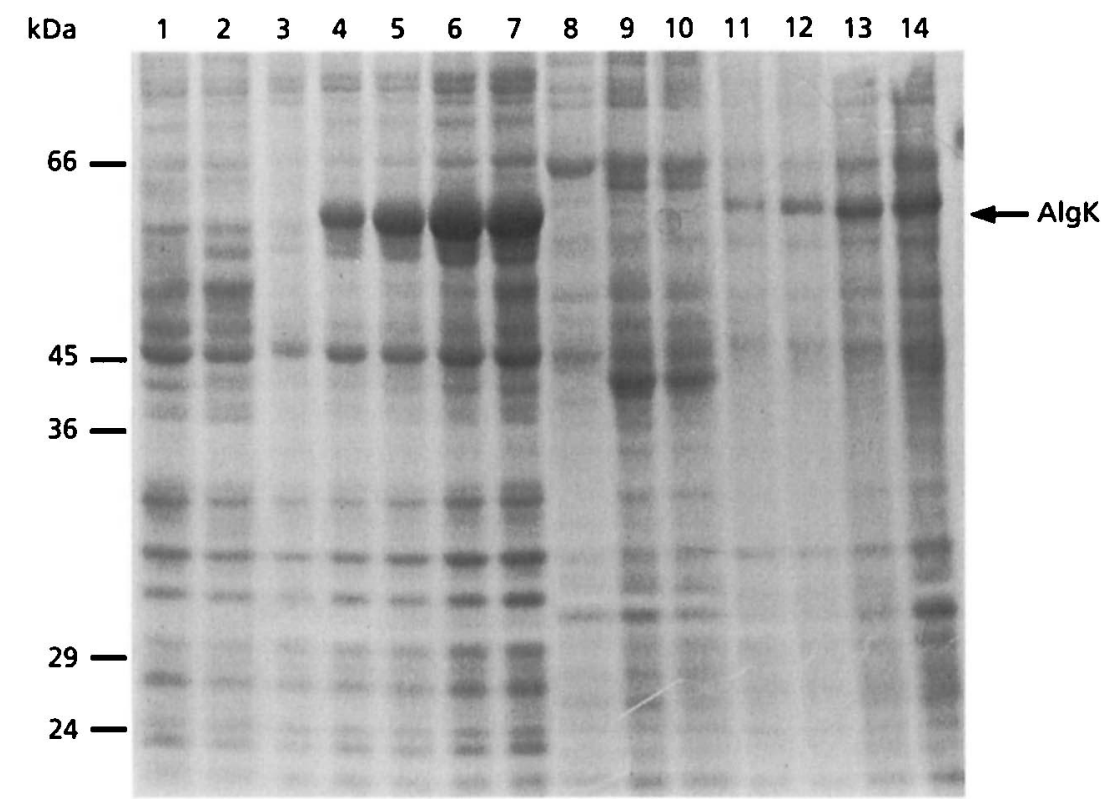

Fig. 3. SDS-PAGE analysis of the expression of AlgK from pAA23 in $P$. aeruginosa PA8873, and $E$. coli HB101. Lanes 1 and 2 show HB101 (pMMB66 EH) treated with IPTG for $4 \mathrm{~h}$ to induce expression from the tac promoter; lanes 3-7 contain HB101(pAA23) treated with IPTG for $0,1,2,3$ and $4 \mathrm{~h}$, respectively. Lanes 8 and 9 contain PA8873 and PA8873(pMMB66 EH) treated with IPTG for $4 \mathrm{~h}$; lanes 10-14 contain PA8873(PAA23) treated with IPTG for $0,1,2,3$ and $4 \mathrm{~h}$, respectively. Cells were lysed, and proteins were separated by SDS-PAGE and stained with Coomassie brilliant blue. Positions of molecular size markers are shown on the left; the protein expressed from algK is indicated by the arrow.

before and subjected to SDS-PAGE. A broad band of $50-53 \mathrm{kDa}$ was observed which was not found in the control samples. This protein band corresponded well with the size of AlgK predicted from the DNA sequence (data not shown).

To determine whether AlgK is expressed in $P$. aeruginosa as it is in E. coli the algK gene was cloned into the broad-host-range expression vector pMMB66(EH). Since the previous experiments predicted that translation may be inefficient, the RBS of pT7-7 was incorporated into the amplified fragment which was cloned into pMMB66(EH). A further synthetic oligonucleotide was designed (primer 3) which primes upstream of both the RBS and the ATG start of algK in pAA20 and also contains an EcoRV restriction site towards the $5^{\prime}$ end of the primer. PCR with primer 3 and primer 2 therefore results in the amplification of the algK gene, containing the strong RBS from pT7-7 with an EcoRV site at the $5^{\prime}$ end, and a BamHI site at the $3^{\prime}$ end. This DNA fragment was cloned into the SmaI-BamHI restriction sites of pMMB66(EH) to form plasmid pAA23. This placed algK under the control of the inducible ptac promoter. Overexpression was carried out in both $E$. coli $\mathrm{HB} 101$ and $P$. aeruginosa PA8873, following the induction protocol used previously with the pT7 vectors. In both $E$. coli and $P$. aeruginosa, an AlgK polypeptide was observed which migrated as seen previously with the pT7 system as a broad band at approximately $50-53 \mathrm{kDa}$ (Fig. 3, lanes 4-7 and 11-14, respectively). This indicated that production of AlgK occurs in a similar manner in both organisms.

\section{In vivo processing of AlgK}

Analysis of the nucleotide sequence of algK suggested that the protein product may undergo processing by leader peptidase II, resulting in removal of a signal

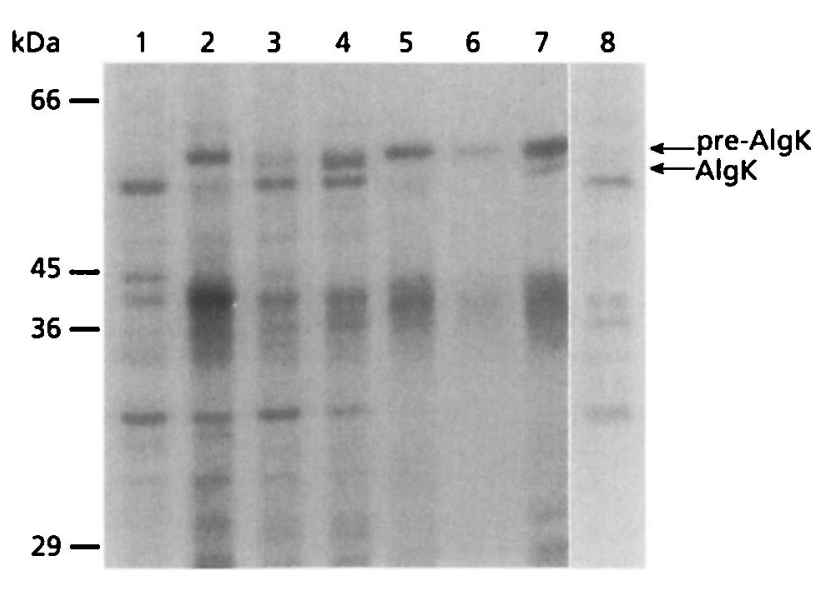

Fig. 4. Autoradiogram of proteins expressed from the T7 promoter in $E$. coli strains BL21(DE3)[pLysS]. Cultures were labelled with $\left[{ }^{35} \mathrm{~S}\right]$ methionine for various periods, denatured in LSB (Laemmli, 1970) and separated by SDS-PAGE. Samples were as follows: lane 1, BL21(DE3)[pLysS, pT7-7] treated with IPTG and labelled with [ ${ }^{35}$ S]methionine for $5 \mathrm{~min}$; lanes 2-4, BL21(DE3)[pLysS, pAA20] treated with IPTG and labelled with $\left[{ }^{35}\right.$ S]methionine for 1,5 and $20 \mathrm{~min}$ respectively; lanes 5-7, BL21(DE3)[pLys5, pAA20] treated with IPTG and rifampicin and labelled with ${ }^{35}$ S]methionine for 1,5 , and $20 \mathrm{~min}$, respectively: lane 8, BL21(DE3)[pLysS, pT7-7] treated with IPTG and rifampicin and labelled with ${ }^{35}$ S methionine for $5 \mathrm{~min}$. Putative AlgK preprotein and mature protein are arrowed. The positions of molecular size markers are shown on the left.

sequence and lipid attachment at the $\mathrm{N}$-terminus of the mature protein. This may explain why a broad band was observed following SDS-PAGE (Fig. 3). In order to examine whether post-translational processing of AlgK was occurring, a series of radiolabelling experiments was performed. Labelling of BL21(DE3)[pLysS, pAA20] with $\left[{ }^{35} \mathrm{~S}\right]$ methionine revealed two polypeptides of approximately 53 and $50 \mathrm{kDa}$ (Fig. 4, lanes $2-4$ and 5-7) 


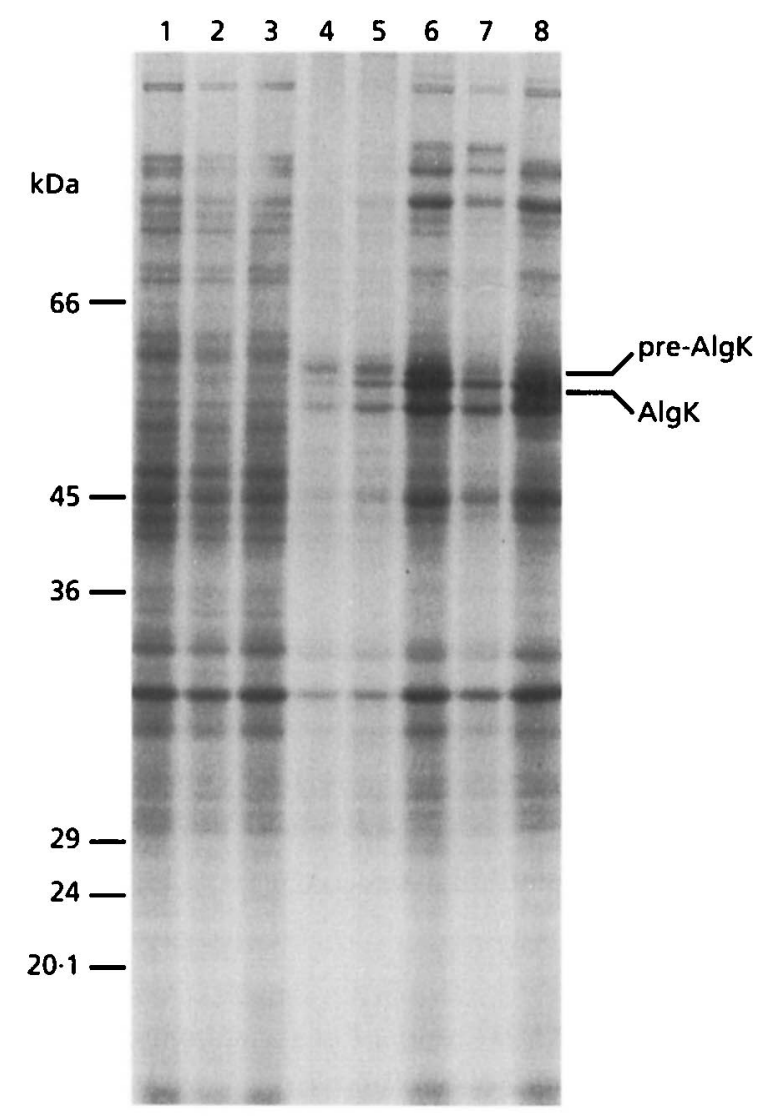

Fig. 5. Autoradiogram of pulse-labelled proteins in $P$. aeruginosa cells expressing algK. Cells were labelled with ${ }^{35} \mathrm{~S}$ ]methionine and then the decay in their proteins was monitored for intervals between 0 and $30 \mathrm{~min}$. Cells were lysed and proteins were separated by SDS-PAGE. Lanes 1, 2, and 3 show PA8873(pMMB66 EH) labelled with [ ${ }^{35}$ S]methionine for $2 \mathrm{~min}$ and then chased for 0,5 and $30 \mathrm{~min}$, respectively, with unlabelled methionine. Lanes 4, 5, 6, 7 and 8 show PA8873(pAA23) labelled with $\left[{ }^{35} \mathrm{~S}\right]$ methionine for $2 \mathrm{~min}$ and then chased for $0,3,5,15$ and $30 \mathrm{~min}$, respectively, with unlabelled methionine. The positions of molecular size markers are shown on the left. Pre-AlgK and AlgK indicate the precursor and mature proteins expressed by algK, respectively.

that were not observed in the control samples (Fig. 4, lanes 1 and 8 ). The size of these correlated well with the inferred sequence of pre-AlgK and mature AlgK.

To provide further evidence for processing, a pulsechase analysis was carried out in $P$. aeruginosa. Cultures of PA8873(pAA23) were initially labelled with $\left[{ }^{35} \mathrm{~S}\right]$ methionine and then incubated in an excess of nonradioactive $\mathrm{L}$-methionine to establish the processing pattern of newly synthesized proteins. Samples were withdrawn at various intervals and analysed by SDSPAGE and autoradiography (Fig. 5). The $53 \mathrm{kDa}$ preAlgK band was observed at the initial $(2 \mathrm{~min})$ time point (Fig. 5, lane 4) and then gradually faded in intensity during the chase period. This decrease correlated with a concomitant increase in intensity of the $50 \mathrm{kDa}$ protein (Fig. 5, lanes 5-8). Overall, this pattern suggested that

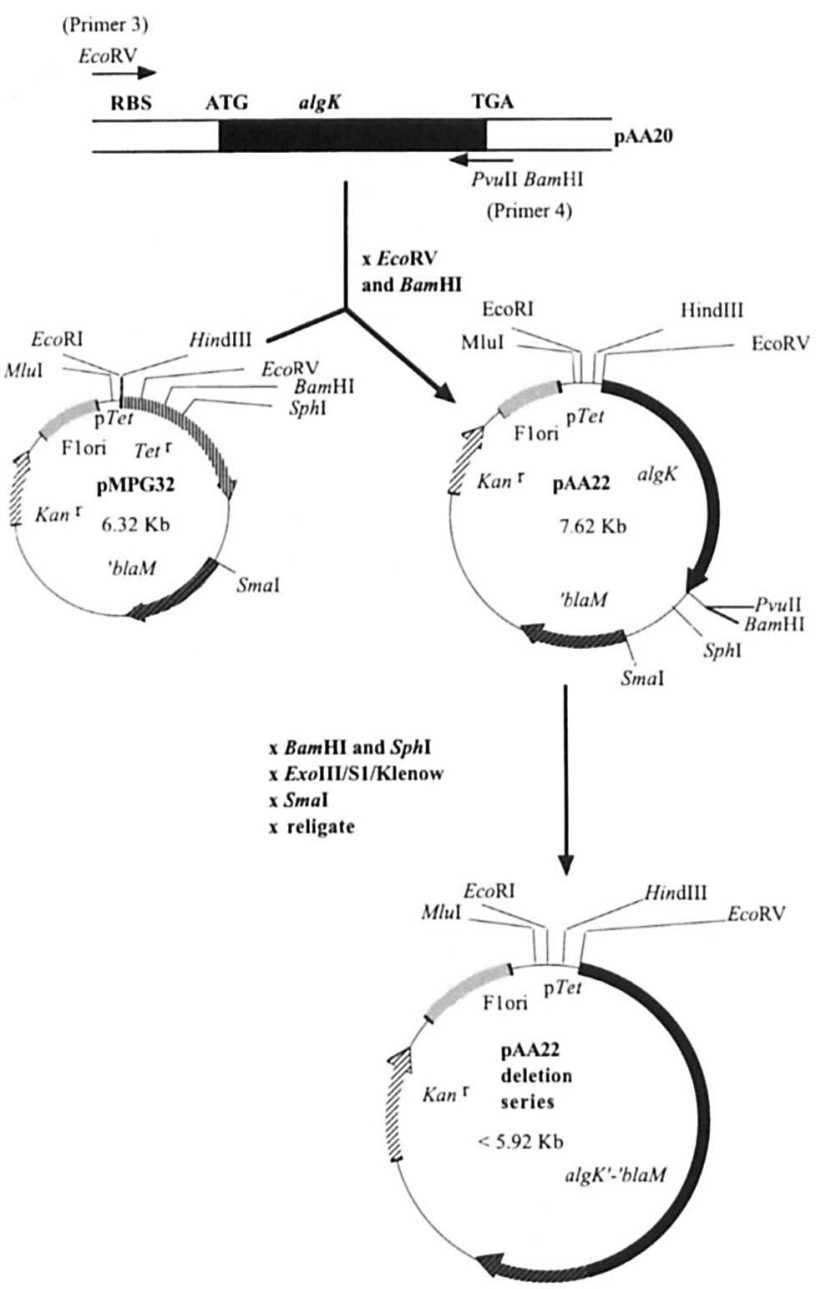

Fig. 6. Construction of pAA35 and the pAA22 series. The algK gene was amplified and subcloned into pMPG32 between the EcoRV and BamHI sites. A directed, in-frame fusion between the full-length alg $K$ gene and blaM was constructed (pAA35) by restriction with Pvull and Smal, followed by ligation. A random series of fusions between the coding region for mature TEM $\beta$ lactamase and fragments of the algK gene was produced by exonuclease deletion from the $3^{\prime}$ end of algK, as described in the text. alg $K^{\prime}-{ }^{\prime} b / a M$ represents an in-frame fusion between part of the algK gene and the coding region for the mature form of TEM $\beta$-lactamase.

AlgK is produced as a preprotein which is subsequently cleaved in both $E$. coli and $P$. aeruginosa, in a manner consistent with processing by signal peptidase II, to give a mature polypeptide of approximately $50 \mathrm{kDa}$.

\section{Analysis of the subcellular location of AlgK}

Sequence analysis and the above studies provided evidence for the processing and possible secretion of AlgK. In order to confirm this intepretation, the subcellular location of AlgK was examined by fusing $\mathrm{N}$ terminal fragments of AlgK to mature $\beta$-lactamase (Fig. 6). Fusion of mature $\beta$-lactamase (which lacks its native signal sequence) to secreted proteins or to domains of 
membrane proteins that are normally orientated on the periplasmic side of the cytoplasmic membrane generally results in the translocation of this enzyme to the periplasm and thereby provides individual cells of $E$. coli with a high degree of resistance to ampicillin (BroomeSmith \& Spratt, 1986). Fusion to a region of polypeptide which does not normally cross the cytoplasmic membrane fails to provide individual cells with resistance to ampicillin as the cytoplasmic $\beta$-lactamase is inappropriately located to protect the penicillin-binding proteins. In this system, single-cell resistance must be assessed, since multicellular droplets of bacteria which express in-frame fusions can normally tolerate $200 \mu \mathrm{g}$ ampicillin $\mathrm{ml}^{-1}$ independently of the subcellular location of the fusion polypeptide. This results from crossprotection arising from limited cell lysis and enzyme release.

In the present study, a derivative of the vector pJBS633, pMPG32 (Broome-Smith \& Spratt, 1986), was used to construct in-frame fusions between the coding region of mature TEM $\beta$-lactamase and that of the algK gene which was partially deleted from the $3^{\prime}$ end. Initially, algK was cloned into pMPG32 to form plasmid pAA22. The algK fragment was amplified by PCR using pAA20 as the DNA source and primers 3 and 4 . Primer 3 was used to allow amplification of algK together with an efficient (pT7-7) RBS. Primer 4 contains BamHI and PvuII restriction sites at the $5^{\prime}$ end of the oligonucleotide and primes immediately downstream and overlapping the complementary sequence of the algK TGA stop codon. The resulting PCR product (algK with flanking $E c o R V$ and $B a m H I$ restriction sites) was cloned into the respective sites of pMPG32. This allows the retention of the tetracycline promoter of pJBS633 which mediates expression of the algK'-'blaM fusions.

Initially a directed translational fusion was generated by digesting pAA22 with PvuII and SmaI, followed by religation. This resulted in plasmid pAA35, in which the entire algK gene was fused in-frame to 'blaM. Additionally, plasmid pAA22 was digested with BamHI and $S p h I$ and then treated with exonuclease III for varying periods, followed by S1 nuclease, to generate a unidirectional set of nested deletions in the $3^{\prime}$ region of algK. The samples were then treated with Klenow polymerase to produce 'blunt ends' and digested with SmaI prior to religation. Kanamycin-resistant, tetracycline-sensitive transformants that expressed putative 'in-frame' $A \operatorname{lgK}-\beta$-lactamase fusions were identified by their ability to grow from multicellular droplets when spotted onto LB-agar containing $200 \mu \mathrm{g}$ ampicillin $\mathrm{ml}^{-1}$. Single-stranded plasmid DNA was subsequently prepared from constructs with 'in-frame' fusions and the positions of the alg $K^{\prime}-{ }^{\prime} b l a M$ fusion junctions were determined by sequencing (Table 2).

The single-cell MICs were then determined and were used to predict the subcellular locations of the $\beta$ lactamase moiety of each of the fusions (Broome-Smith $\&$ Spratt, 1986). From Table 2 it can be seen that fusion proteins which contained 42 or more residues of $\mathrm{AlgK}$
Table 2. In-frame junctions of each algK'-'blaM fusion as determined by nucleotide sequencing

The MIC of ampicillin required to lyse single cells of JM101 expressing individual fusion proteins is indicated and the position of the $\beta$-lactamase moiety of each fusion as inferred from the single cell MIC is shown alongside.

\begin{tabular}{|lcl|}
\hline $\begin{array}{l}\text { Position of } \\
\text { fusion junction }\end{array}$ & $\begin{array}{c}\text { MIC } \\
\text { of ampicillin } \\
\left(\mu \mathrm{g} \mathrm{ml}^{-1}\right)\end{array}$ & $\begin{array}{c}\text { Proposed } \\
\text { subcellular } \\
\text { location of } \\
\text { domains }\end{array}$ \\
\hline Pro $^{7}$ & $<5$ & Cytoplasmic \\
$\mathrm{Glu}^{42}$ & $>800$ & Periplasmic \\
$\mathrm{Gln}^{50}$ & $>800$ & Periplasmic \\
$\mathrm{Gln}^{80}$ & $>800$ & Periplasmic \\
$\mathrm{Lys}^{86}$ & $>800$ & Periplasmic \\
$\mathrm{Ser}^{125}$ & $>800$ & Periplasmic \\
$\mathrm{Leu}^{284}$ & $>800$ & Periplasmic \\
$\mathrm{Gln}^{291}$ & $>800$ & Periplasmic \\
$\mathrm{Ala}^{388}$ & $>800$ & Periplasmic \\
$\mathrm{AlgK}^{476}$ & $>800$ & Periplasmic \\
\hline
\end{tabular}

conferred substantial ampicillin resistance upon single cells of $E$. coli, suggesting that the $\beta$-lactamase moiety of each of these fusions is located in the periplasm. This result predicts that the carboxy terminus of $\mathrm{AlgK}$, from residues 42 onwards, is located on the periplasmic side of the cytoplasmic membrane. In contrast, E. coli cells expressing fusion protein with only seven residues of AlgK showed no increase in single-cell MIC, indicating that the $\beta$-lactamase moiety of this fusion protein was not translocated to the periplasm. The latter cells did, however, produce enzymically active fusion proteins since they could withstand $200 \mu \mathrm{g}$ ampicillin $\mathrm{ml}^{-1}$ when plated as multicellular droplets. These data are consistent with the production of an AlgK pre-protein which is secreted into the periplasm together with the removal of a signal sequence.

\section{Immunodetection of AlgK- $\beta$-lactamase fusion proteins produced in $E$. coli}

As further evidence for the continuity of the algK ORF and also that the interpretation of the MIC data was correct, the in-frame AlgK- $\beta$-lactamase fusion proteins were examined by immunoblotting, using antisera against TEM- $\beta$-lactamase and an anti-IgG antibodyalkaline phosphatase detection system. In each case, fusion proteins which contained 42 or more residues of AlgK were observed to migrate to positions approximately $3 \mathrm{kDa}$ smaller than would be predicted from the molecular mass of the unprocessed fusion protein (Fig. 7). In contrast, the fusion containing only seven amino acids from the $\mathrm{N}$-terminus of AlgK ran as predicted. This result is consistent with the cleavage and removal of a signal peptide within the first 42 amino acids of 


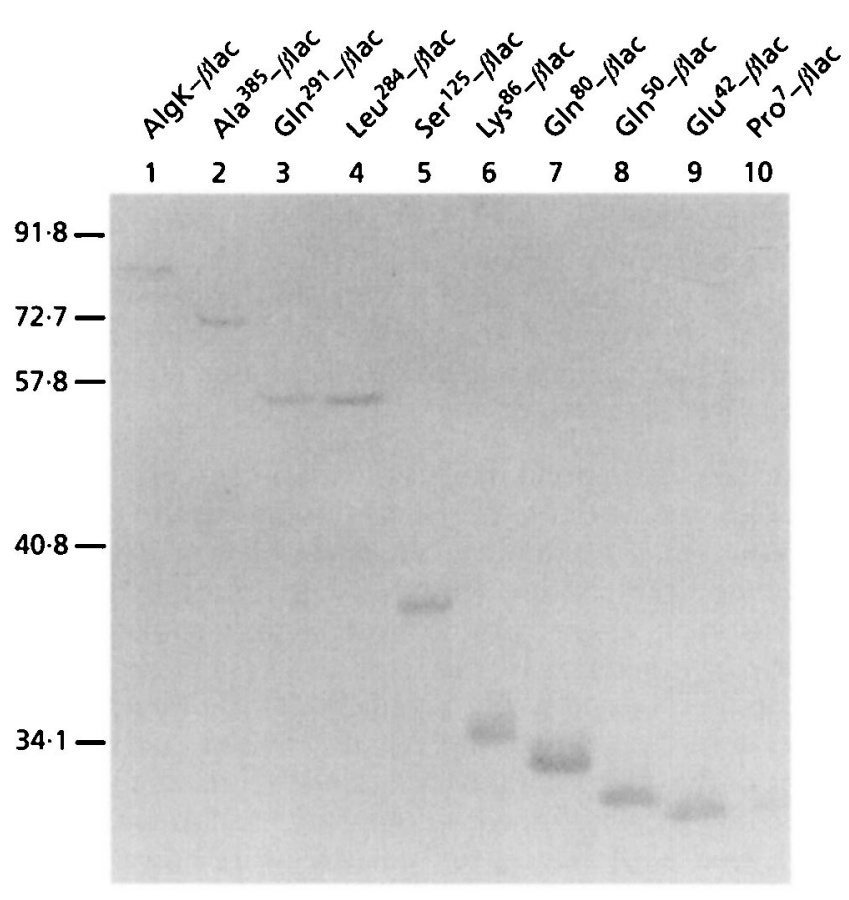

Fig. 7. Detection of AlgK and truncated AlgK- $\beta$-lactamase fusion proteins. Cultures of strain JM101, containing pAA35 or pAA22 derivatives carrying in-frame alg $K^{\prime}-{ }^{\prime} b l a M$ translational fusions, were grown overnight. Cells were harvested, denatured with sample buffer (Laemmli, 1970) and equal loadings were run on a $10 \%$ SDS-polyacrylamide gel. The gel was immunoblotted using anti- $\beta$-lactamase antibodies, followed by detection with alkaline phosphate-conjugated goat anti-rabbit IgG. The positions of molecular size markers are indicated on the left.

AlgK. In samples containing pAA35 (Fig. 7, lane 1), two high-molecular-mass AlgK- $\beta$-lactamase fusion proteins were clearly visible, with the upper band being approximately $3 \mathrm{kDa}$ larger than the lower band. This suggests that both the unprocessed and the mature forms of the fusion protein are present.

\section{Insertional inactivation of algK results in loss of alginate production}

To evaluate whether algK was required for alginate production the chromosomal algK gene was disrupted by insertional inactivation, using pBR325 as a suicide vector. An algK fragment of 460 bp was amplified from pAA22 using primer 7 , which contains a PstI site towards the $5^{\prime}$ end, and primer 4, and then digested with PstI before subcloning into the corresponding site of pBR325. Single homologous recombinants were selected on minimal plates, containing $200 \mu \mathrm{g}$ tetracycline $\mathrm{ml}^{-1}$, following transfer of pAA31 into $P$. aeruginosa strain B $(\mathrm{PAB})$, which constitutively secretes alginate, by triparental mating. The resulting isolates (PABK) were non-mucoid when plated on LB agar or MAP medium, which promotes alginate production (Franklin et al., 1994).
Previous studies (Chitnis \& Ohman, 1993) indicated that insertional inactivation of genes in the alginate gene cluster may cause polar effects on downstream gene expression and result in loss of mucoidy. Since the algE and $\operatorname{alg} A$ genes which lie downstream from $\operatorname{alg} K$ are essential for alginate production (Chu et al., 1991; Darzins et al., 1986), the possibility that absence of mucoidy observed with PABK reflected a polar effect of the algK disruption was explored. A SmaI-HindIII fragment which spans from the 3 ' end of alg44 into algG, and contains the entire algKE region, was therefore cloned from pRM812 into the broad-host-range vector pMMB66(EH), forming pAA32. The HindIII fragment from pAD4038 which carries the algA gene was then inserted into the corresponding site in pAA32. The resulting plasmid, pAA33, was mobilized into PABK by triparental mating and exconjugants were selected on minimal agar containing tetracycline and ampicillin. Expression of algKEA was induced from the ptac promoter of pAA33 on LB plates or MAP plates containing IPTG. However, no evidence for restoration of a mucoid phenotype was observed.

\section{DISCUSSION}

The present study describes the cloning and sequencing of a new gene, algK. This gene is found in a $2 \mathrm{~kb}$ SmaI-EcoRI fragment located between alg44 and algE. The cloned DNA contains a 1425 bp ORF that codes for a 475 amino acid hydrophilic protein of $52470 \mathrm{Da}$ and is transcribed in the same orientation as the other genes of the operon.

Expression of algK from its natural RBS in E. coli, with vector pT7-5, did not result in detectable AlgK polypeptide. However, when a strong RBS was utilized for expression, a broad band of $50-53 \mathrm{kDa}$ was observed, suggesting that the RBS of algK is relatively weak. However, it cannot be excluded that the short intergenic region ( $227 \mathrm{bp}$ ) which lies between alg44 and algK may influence polypeptide production. Sequence analysis also revealed overlap between the translational stop codon of $\operatorname{algK}$ and the start codon of algE and suggests that translational coupling may occur. It seems likely therefore that the product of algE would also be produced in relatively low abundance. This is in agreement with previous studies on AlgE (Grabert et al., 1990) and therefore may indicate that the intergenic region or other factors play a role in controlling the level of AlgK production.

Analysis of the putative amino acid sequence revealed a consensus lipoprotein cleavage site and predicted that a pre-protein of approximately $53 \mathrm{kDa}$ is synthesized which would undergo removal of an N-terminal signal sequence, together with lipidation of the mature polypeptide (approximately $50 \mathrm{kDa}$ ) and targeting of the protein outwith the cytoplasm. However, high-level expression of the AlgK protein in E. coli or P. aeruginosa revealed only a single, broad protein band of $50-53 \mathrm{kDa}$ (Fig. 3). $\left[{ }^{35} \mathrm{~S}\right]$ Methionine labelling of the protein product 
(Figs 4 and 5) provided evidence that post-translational cleavage of AlgK did indeed occur and suggested that the single broad band observed previously represented a mixture of the unprocessed and processed forms of $\mathrm{AlgK}$.

Construction of $\mathrm{AlgK}-\beta$-lactamase fusion proteins and detection by immunoblotting predicted a periplasmic orientation for the AlgK protein and provided further evidence for the presence of a cleavable signal sequence within the $\mathrm{N}$-terminal 42 amino acids and also, for processing of larger fusion proteins (Fig. 7). However, although the AlgK- $\beta$-lactamase fusion survey predicted that mature AlgK was entirely periplasmic, it gave no clue as to whether this lipoprotein was anchored to the outer face of the inner membrane or the inner face of the outer membrane. However, the studies of Grabert $e t$ al. (1990) suggest that AlgK is most likely anchored to the inner membrane. In an extensive survey on mucoid and non-mucoid revertants of $P$. aeruginosa strains, they found one novel protein band in the outer membrane of mucoid strains. Sequencing of algE (Chu et al., 1991) showed that this novel $54 \mathrm{kDa}$ outer-membrane protein corresponded to the $\mathrm{AlgE}$ protein. AlgK was not detected in the outer membrane (Grabert et al., 1990), suggesting that $\mathrm{AlgK}$ is anchored to the cytoplasmic membrane.

Immediately upstream of algK lie the alg44 and alg8 genes. The amino acid sequences of the proteins encoded by these genes (as predicted from their nucleotide sequences) previously led to the suggestion that they have a cytoplasmic membrane orientation and play a role in mannuronate polymerization (Maharaj et al., 1993). More recently, hydrophobic cluster analysis (Saxena et al., 1995) revealed that Alg8 was similar in overall structure and thus possibly function to the putative polymerization region of AcsAB, the Acetobacter xylinum cellulose synthase, and thus belonged to a family of $\beta$-glycosyltransferases. No innermembrane transport protein for cellulose synthesis has been identified but the model proposed by Ross et al. (1991) suggests that the cellulose synthase protein may be associated with both polymerization and transport of the polymer across the inner membrane. Whether such a dual role exists for the other proposed members of this family, chitin synthase of Saccharomyces cerevisiae (Bulawa et al., 1986), hyaluronic acid synthase of group A streptococci (Dougherty \& van de Rijn, 1994) and NodC of Azorbizobium caulinodans (Geremia et al., 1994), or whether additional components are required which may mediate polymer transport, remains to be determined.

The location of genes encoding the periplasmic-oriented AlgK protein and the outer-membrane alginatepermeable pore (AlgE) directly downstream of genes encoding a putative mannuronate polymerase/ cytoplasmic polymannuronate transporter is remarkably similar to the genetic arrangements of other polysaccharide export systems from other organisms. These include the acs locus (Saxena et al., 1994), the cellulose synthase and transport operon of A. xylinum, the bex (b capsule expression) operon of Haemophilus influenza (Kroll et al., 1990) and the ctr (capsule polysaccharide transport region) operon of Neisseria meningitidis (Frosch et al., 1991). In each case, these operons encode a single periplasmic protein component which is considered to be associated with the periplasmic transport of the polysaccharide. It therefore seems highly likely that AlgK may also function similarly, and as such may act as a periplasmic facilitator to channel alginate through the periplasmic space to the outer-membrane pore of $P$. aeruginosa, AlgE.

In order to gain preliminary information on the function of $\mathrm{AlgK}$ and also to evaluate its importance for alginate production, we examined the effect of gene disruption on exopolysaccharide synthesis. Disruption of algK by insertion of a selectable cassette which conveys antibiotic synthesis was observed to result in loss of mucoidy. However, the possibility that this approach also abolished expression of an essential downstream gene of the operon cannot be excluded. Efforts to restore mucoidy by simultaneous complementation with algK, $\operatorname{alg} E$ and $\operatorname{alg} A$ have been unsuccessful; however, the studies of Darzins et al. (1985) on alg60 have suggested that the latter gene is also necessary for alginate production and this may explain our observations.

At present, the most likely role of $\mathrm{AlgK}$ would therefore seem to be to act as a facilitator to translocate alginate across the periplasm. Whether such a facilitator function would require that the alginate remains accessible for acetylation during this process, or whether this modification may occur prior to translocation across the periplasm, remains to be determined.

\section{ACKNOWLEDGEMENT}

S. J.A. was the holder of a BBSRC studentship.

\section{REFERENCES}

Boyd, A., Ghosh, M., May, T. B., Shinabarger, D., Keogh, R. \& Chakrabarty, A. M. (1993). Sequence of the algL gene of Pseudomonas aeruginosa and purification of its alginate lyase product. Gene 131, 1-8.

Broome-Smith, J. K. \& Spratt, B. G. (1986). A vector for the construction of translational fusions to TEM $\beta$-lactamase and the analysis of protein export signals and membrane topology. Gene 49, 341-349.

Bulawa, C. E., Slater, M., Cabib, E., Auyoung, J., Sburlati, A. \& Adair, W. L. (1986). The $S$. cerevisiae structural gene for chitin synthase is not required for chitin synthesis in vivo. Cell 46, 213-225.

Chitnis, C. E. \& Ohman, D. E. (1993). Genetic analysis of the alginate biosynthetic cluster of Pseudomonas aeruginosa shows evidence of an operonic structure. Mol Microbiol 8, 583-590.

Chu, L., May, T. B., Chakrabarty, A. M. \& Misra, T. K. (1991). Nucleotide sequence and expression of the $\operatorname{alg} E$ gene involved in alginate biosynthesis by Pseudomonas aeruginosa. Gene 107, 1-10.

Darzins, A. \& Chakrabarty, A. M. (1984). Cloning of genes 
controlling alginate biosynthesis from a mucoid cystic fibrosis isolate of Pseudomonas aeruginosa. J Bacteriol 166, 9-18.

Darzins, A., Wang, S.-K., Vanags, R. I. \& Chakrabarty, A. M. (1985). Clustering of mutations affecting alginic acid biosynthesis in mucoid Pseudomonas aeruginosa. J Bacteriol 167, 516-524.

Deretic, V., Gill, G. F. \& Chakrabarty, A. M. (1987). Pseudomonas aeruginosa infection and cystic fibrosis: nucleotide sequence and transcriptional regulation of the algD gene. Nucleic Acids Res 15, 4567-4581.

Dougherty, B. A. \& van de Rijn, I. (1994). Molecular characterisation of has $A$ from an operon required for hyaluronic acid synthesis in group A streptococci. J Biol Chem 269, 169-175.

Figurski, D. H. \& Helinski, D. R. (1979). Replication of an origincontaining derivative of plasmid pRK2 dependent on a plasmid function provided in trans. Proc Natl Acad Sci USA 76, 1648-1652.

Franklin, M. J., Chitnis, C. E., Gacesa, P., Sonesson, A., White, D. C. \& Ohman, D. E. (1994). Pseudomonas aeruginosa AlgG is a polymer level alginate C5-mannuronan epimerase. $J$ Bacteriol 176, 1821-1830.

Frosch, M., Edwards, V., Bousset, K., Kraube, B. \& Weisgerber, C. (1991). Evidence for a common molecular origin of the capsule gene loci in Gram-negative bacterial expressing group II capsular polysaccharides. Mol Microbiol 5, 1251-1263.

Fürst, J. P., Pansegrau, W., Frank, R., Blocker, H., Shoiz, P., Bagdasarian, M. \& Lanka, E. (1986). Molecular cloning of the plasmid RP4 primase region in multi-host-range tacP expression vector. Gene 48, 119-131.

Geremia, R. A., Mergaert, P., Geelen, D., Vanmontagu, M. \& Holsters, M. (1994). The NodC protein of Azorhizobium caulinodans is an $\mathrm{N}$-acetylglucosaminyltransferase. Proc Natl Acad Sci USA 91, 2669-2673.

Grabert, E., Wingender, J. \& Winkler, U. K. (1990). An outer membrane protein characteristic of mucoid strains of Pseudomonas aeruginosa. FEMS Microbiol Lett 68, 83-88.

Hayashi, S., Chang, S.-Y., Chang, S. \& Wu, H. C. (1984). Modification and processing of Bacillus licheniformis prepenicillinase in Escherichia coli. Fate of mutant penicillinase lacking a lipoprotein modification site. J Biol Chem 259, 10448-10454.

Henikoff, S. (1987). Unidirectional digestion with exonuclease III in DNA sequence analysis. Methods Enzymol 155, 156-165.

Knecht, D. A. \& Dimond, R. L. (1984). Visualisation of antigenic proteins on Western Blots. Anal Biochem 136, 180-184.

Kroll, J. S., Loynds, B., Brophy, L. N. \& Moxon, E. R. (1990). The bex locus in encapsulated Haemophilus influenzae: a chromosomal region involved in capsule polysaccharide export. Mol Microbiol 4, 1853-1862.

Laemmli, U. K. (1970). Cleavage of structural proteins during the assembly of the head of bacteriophage T4. Nature 227, 680-685.

Lam, J., Chan, R. \& Costerton, J. W. (1980). Production of mucoid microcolonies by Pseudomonas aeruginosa within infected lungs in cystic fibrosis. Infect Immun 28, 546-556.

Maharaj, R., May, T. B., Wang, S.-K. \& Chakrabarty, A. M. (1993). Sequence of alg8 and alg44 genes involved in the synthesis of alginate by Pseudomonas aeruginosa. Gene 136, 267-269.

Maniatis, T., Frisch, E. \& Sambrook, J. (1982). Molecular Cloning: a Laboratory Manual. Cold Spring Harbor, NY: Cold Spring Harbor Laboratory.

May, T. B. \& Chakrabarty, A. M. (1994). Pseudomonas aeruginosa: genes and enzymes of alginate synthesis. Trends Microbiol 2, 151-156.
Minton, N. P., Atkinson, T., Brunton, C. J., Sherwood, R. F. (1984). The complete nucleotide sequence of the Pseudomonas gene coding for carboxypeptidase-G2. Gene 31, 31-38.

Pugsley, A. P. (1993). The complete general secretory pathway in Gram-negative bacteria. Microbiol Rev 57, 50-108.

Rehm, B. H. A., Boheim, G., Tommassen, J. \& Winkler, U. K. (1994). Overexpression of algE in Escherichia coli: subcellular localisation, purification and ion channel properties. J Bacteriol 176, 5639-5647.

Ross, P., Mayer, R. \& Benziman, M. (1991). Cellulose biosynthesis and function in bacteria. Microbiol Rev 55, 35-38.

Russel, M., Kidel, S. \& Kelley, M. R. (1986). An improved filamentous helper phage for sequencing single stranded plasmid DNA. Gene 45, 333-338.

Sambrook, J., Fritsch, E. F. \& Maniatis, T. (1989). Molecular Cloning, a Laboratory Manual, 2nd edn. Cold Spring Harbor, NY: Cold Spring Harbor Laboratory.

Sanger, F., Nicklen, S. \& Coulson, A. R. (1977). DNA sequencing with chain-terminating inhibitions. Proc Natl Acad Sci USA 74, 5463-5467.

Saxena, I. M., Kudlicka, K., Okuda, K. \& Brown, R. M. (1994). Characterisation of genes in the cellulose synthesising operon (acs operon) of Acetobacter xylinum: implications for cellulose crystallisation. J Bacteriol 176, 5735-5752.

Saxena, I. M., Brown, M. B., Fevre, M., Geremia, R. A. \& Henrissat, B. (1995). Multidomain architecture of $\beta$-glycosyl transferases: implications for mechanisms of action. $J$ Bacteriol 177, 1419-1424.

Schiller, N. L., Monday, S. R., Boyd, C. M., Keen, N. T. \& Ohman, D. E. (1993). Characterisation of the Pseudomonas aeruginosa alginate lyase gene $(a \lg L)$ : cloning, sequencing and expression in Escherichia coli. J Bacteriol 175, 4780-4789.

Shinabarger, D., Berry, A., May, T. B., Rothmel, R., Fialho, A. \& Chakrabarty, A. M. (1991). Purification and characterisation of phosphomannose isomerase guanosine diphospho-D-mannose pyrophosphorylase. J Biol Chem 266, 2080-2088.

Shinabarger, D., May, T. B., Boyd, A., Ghosh, M. \& Chakrabarty, A. M. (1993). Nucleotide sequence and expression of the Pseudomonas aeruginosa algF gene controlling acetylation of alginate. Mol Microbiol 9, 1027-1035.

Short, J. M., Fernandez, J. M., Sorge, J. A. \& Huse, W. D. (1988). $\lambda$ ZAP: a bacteriophage 1 expression vector with in-vivo excision properties. Nucleic Acids Res 16, 7583-7600.

Skjăk-Bræk, G., Grasdalen, H. \& Larsen, B. (1986). Monomer sequence and acetylation patterns in some bacterial alginates. Carbohydrate Res 154, 239-250.

Southern, E. M. (1975). Detection of specific sequences among DNA fragments separated by gel electrophoresis. J Mol Biol 98, 503-517.

Studier, F. W. \& Moffatt, B. A. (1986). Use of bacteriophage T7 RNA polymerase to direct selective, high-level expression of cloned genes. J Mol Biol 189, 113-130.

Studier, F. W., Rosenberg, A. H., Dunn, J. J. \& Dubendorf, J. W. (1990). Use of T7 RNA polymerase to direct expression of cloned genes. Methods Enzymol 185, 60-89.

Tabor, S. (1990). Expression using the T7 RNA polymerase promoter system. In Current Protocols in Molecular Biology, pp. 16.0.1-16.2.11. Edited by F. M. Ausubel, R. Brent, R. E. Kingston, D. M. Moore, J. G. Seidman, J. A. Smith \& K. Strahl. New York: Greene Publishing Associates. 
Towbin, H., Staehelin, T. \& Gordon, J. (1979). Electrophoretic transfer of proteins from polyacrylamide gels to nitrocellulose sheets : procedure and some applications. Proc Natl Acad Sci USA 76, 4350-4354.

Yanisch-Perron, C., Vieira, J. \& Messing, J. (1985). Improved M13 phage cloning vectors and host strains: nucleotide sequences of the M13 mp18 and pUC19 vectors. Gene 33, 103-109.

Received 9 July 1996; accepted 11 September 1996. 